\title{
Preparation, Physicochemical Characterization, and Bioactivity Evaluation of Strontium-Containing Glass Ionomer Cement
}

\author{
Masomeh Khaghani, ${ }^{1}$ Ali Doostmohammadi, ${ }^{2}$ Zahra Golniya, \\ Ahmad Monshi, ${ }^{3}$ and Ahmad Reza Arefpour ${ }^{1}$ \\ ${ }^{1}$ Department of Materials Engineering, Najafabad Branch, Islamic Azad University, P.O. Box 517, Isfahan, Iran \\ ${ }^{2}$ Materials Department, Engineering Faculty, Shahrekord University, Shahrekord, Iran \\ ${ }^{3}$ Materials Engineering Department, Isfahan University of Technology, Isfahan 84156-83111, Iran \\ Correspondence should be addressed to Ali Doostmohammadi; alidstm@gmail.com
}

Received 9 July 2013; Accepted 26 July 2013

Academic Editors: M. Kawashita, A. Ravaglioli, and P. Valerio

Copyright (C) 2013 Masomeh Khaghani et al. This is an open access article distributed under the Creative Commons Attribution License, which permits unrestricted use, distribution, and reproduction in any medium, provided the original work is properly cited.

Background. Glass ionomer cements are one of the most important restorative materials in dentistry. One of the disadvantages of glass ionomer cements is their undesirable mechanical properties and bioactivity. Aim. The aim of this work was preparation and characterization of strontium-containing glass ionomer cement and evaluation of its bioactivity in the simulated body fluid. Materials and Methods. The ceramic component of glass ionomer cement was made by melting method. Scanning electron microscope (SEM) was used to study the size and the shape of glass particles. In order to determine the phase combination in the produced material, X-ray diffraction (XRD) analysis was carried out. The chemical composition of the glass was evaluated by X-ray florescence (XRF), and the surface area of the particles was determined using BET method. In order to investigate the biological properties of the glass, samples were immersed in simulated body fluid (SBF). Fourier transform infrared spectroscopy (FTIR) and scanning electron microscope (SEM) were used to recognize and confirm the apatite layer on the composite surface. Results and Conclusions. The result of X-ray diffraction (XRD) analysis confirmed the glassy structure of the produced ionomer cements. The result of XRF confirmed the presence of Sr in the chemical composition. Fourier transform infrared spectroscopy test and electron microscope confirmed the formation of apatite layer on the surface of material. The final result of this research was gaining glass ionomer cement containing Sr with improved bioactivity.

\section{Introduction}

Due to desirable characteristics such as chemical-physical bonding to hydrophilic tissues of enamel and dentine, microleakage reduction, long-term release of fluoride, capability of absorbing fluoride and storing it, low thermal expansion coefficient, and biocompatibility with pulp and gum tissues, use of glass ionomer cements is increasing in recent years [1-3].

Despite the mentioned advantages, this kind of materials has disadvantages too that limit their use in some areas. One of their disadvantages is their brittleness that, as a result, the material has no resistive capability against chewing forces. The other main disadvantages of these materials could be regarded as long-term hardening, sensitivity to humidity (that requires water balancing maintenance during working with these materials), surface roughness, lack of adequate strength, high erosion, opaqueness, and short life. Enormous efforts have been done since the invention of glass ionomer to modify the defects, such that most of the problems today have been rectified in new glass ionomers [3-5]. The glass ionomer cement compounds are complex and variable, and two commercial samples are not even similar with regard to their compounds, and they may also be different qualitatively. But, some chemical characteristics are common in these materials. The main material forming glass ionomer cement is calcium fluoroaluminosilicate. The approximate compound of a common glass ionomer is shown in Table 1 [6]. The three main forming parts of applicable glass ionomer cements in dentistry include silica $\left(\mathrm{SiO}_{2}\right)$, alumina $\left(\mathrm{Al}_{2} \mathrm{O}_{3}\right)$, and calcium 
TABLE 1: Conventional composition of calcium fluoroaluminosilicate glass ionomer cements [7].

\begin{tabular}{lcc}
\hline $\mathrm{Wt} \%$ & Chemical composition & Compounds \\
\hline 29 & $\mathrm{SiO}_{2}$ & Quartz \\
16.6 & $\mathrm{Al}_{2} \mathrm{O}_{3}$ & Alumina \\
34.2 & $\mathrm{CaF}_{2}$ & Fluorite \\
5 & $\mathrm{Na}_{3} \mathrm{AlF}_{6}$ & Kerolite \\
5.3 & $\mathrm{AlF}_{3}$ & Aluminum fluoride \\
9.9 & $\mathrm{AlPo}_{4}$ & Aluminum phosphate \\
\hline
\end{tabular}

fluoride that, when bound together, create an appropriate glassy structure for forming the cement. Fluoride is one of the essential forming parts of dentistry glass ionomer cement, since this material affects the melting point of glass ionomers, characteristics of working with the material, and final physical specifications. On the other hand, existence of fluoride increases remineralization in adjacent tooth structure. The fluoride content of glass ionomers could be varied, and even a small reduction in the amount of fluoride could increase translucence without decreasing remineralization. Lanthanum (La) in some glass ionomers is added to the power compound to increase opaqueness against rays and strontium (Sr) and has replaced calcium for the same purpose in some others. Since strontium (Sr) and calcium are close to each other in the periodic table, they behave similarly, and replacing apatite strontium is possible in the tooth structure [6].

Opacity against rays is obtained by melting of metals such as barium, strontium, or lantium together with glass particles (similar to cermet) or mixing glass power with dental amalgam alloy or zinc oxide $[6,8,9]$. There are also reports about the effects of strontium on mechanical properties of glass ionomer cements [7]. The aim of this research is preparation and characterization of a strontium-containing glass ionomer cement and evaluating its bioactivity in the simulated body fluid.

\section{Materials and Methods}

The used primary materials in this research for producing the ceramic part of glass ionomer include aluminum oxide $\left(\mathrm{Al}_{2} \mathrm{O}_{3}\right)$, silicon oxide $\left(\mathrm{SiO}_{2}\right)$, fluoride strontium $(\mathrm{SrF})$, aluminum phosphate $\left(\mathrm{AlPO}_{4}\right)$, and calcium fluoride $\left(\mathrm{CaF}_{2}\right)$ with the purity of $99.8 \%$. All the raw materials were produced by Merck Co. (Germany). The ceramic part of glass ionomer cement was produced by the melting method. First, a defined weight percentage of the mentioned oxides was prepared and mixed in a ball mill with aluminum balls for homogenizing the powders with each other. Then, a defined amount of raw materials were placed in an electric melting furnace (Atash, 1500) and heated for three hours with the rate of $5^{\circ} \mathrm{C} / \mathrm{min}$, to reach the temperature of $1400^{\circ} \mathrm{C}$. For the melting of materials, an alumina pot was used, thus, in the condition that the determined amount of raw materials was in the pot at the temperature of $1400^{\circ} \mathrm{C}$; a series of chemical reactions including melting, decomposition, and oxidation took place. Melted glass resulted from melting the mentioned crystalline materials at $1400^{\circ} \mathrm{C}$. The glass was cooled at ambient temperature and underwent shattering process for 5 hours in a ball mill (Fritsch, Pulverisette 5) with zirconium chamber resistant to erosion and by observing parameters such as the ratio of the ball to powder, number of balls, and rotational speed. The obtained powder at this stage was passed through a 200 mesh sieve (equivalent to $76 \mu)$ in order to be defined as glass powder according to ASTM [10]. The obtained powder is the ceramic part of glass ionomer cement. The produced ceramic powder in the next stage was mixed with a polymer liquid (polyacrylic acid) and the glass ionomer samples were prepared for the tests. First, the glass ionomer powder was dispersed on a cool plate for preparing the samples. Then, half of the dispersed powder was placed slowly into the polymer liquid (polyacrylic acid) and mixed rapidly at a time of 20 seconds. Then, the second part of the powder was placed completely into the mixture that took place only in 20 seconds. The final mixture had a shiny and wet surface, and the working time on it was about 30 to 45 seconds at this stage. Afterwards, the final mixture was poured into aluminum molds with the height of $6 \mathrm{~mm}$ and diameter of $4 \mathrm{~mm}$. After proper drying, the samples were removed from the molds, prepared for the next test stages. Measuring the specific surface area of glass ionomer powder particles was carried out using BET method (Sorptometer Kelvin 1042, Costech), and the density of the produced glass ionomer particles was measured using the replacing method of fluid (Archimedes). X-ray fluorescence elemental analysis (XRF, Bruker, S4 PIONEER, Germany) was used to confirm the presence of oxides in the final compound of glass ionomer powder. Also the phase and glassy structure of glass ionomer powder were analyzed by X-ray diffraction analysis (XRD, Philips Xpert). To analyze the morphology and microstructure of the cement powder, a scanning electron microscope (SEM, Seron Technology, AIS 2100) was used. Finally, for evaluating and confirmation of the glass ionomer powder bioactivity, the glass particles were soaked in the simulated body fluid (SBF). The amount of apatite formation (as the sign of bioactivity) on the glass cement powder was considered after 28 days of soaking in the simulated body fluid, by fourier transform infrared spectroscopy (FTIR, 6300, JASCO, Japan) and scanning electron microscope (SEM) [11].

\section{Results}

3.1. Phase Analysis (XRD). The pattern of X-ray diffraction from glass ionomer powder sample is shown in Figure 1 (before compounding with the polymer liquid). As observed from the figure, no apparent peak was detected in the pattern of X-ray diffraction. This was an indication of amorphic and glassy structure of the produced glass ionomer powder.

3.2. Measuring the Specific Surface Area (BET). The specific surface area of the produced glass ionomer particles that was measured by BET (Brunauer-Emmett-Teller) method was $0.73 \mathrm{~m}^{2} /$ gr. Assuming spherical shape and similar size of the particles, the average of the glass ionomer particles sizes could 


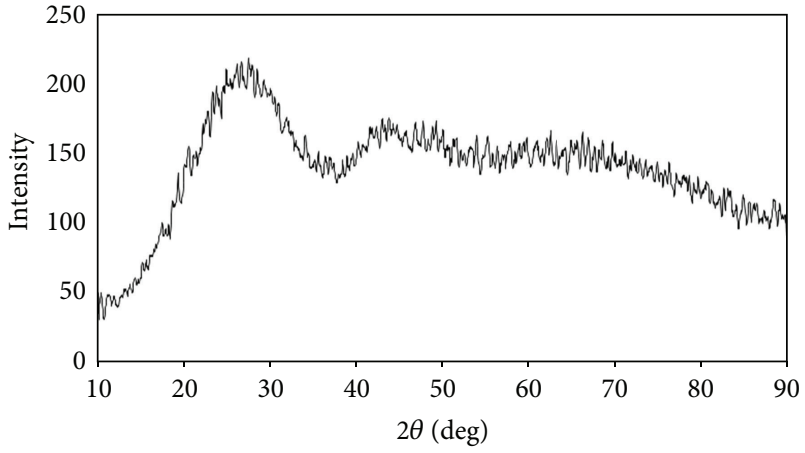

FIGURE 1: X-ray diffraction analysis of glass ionomer powder.

be calculated by [12]

$$
D=\frac{6}{S * \rho},
$$

where " $D$ " is the average dimension of particles in micron, " $S$ " is the measured value by equipment (BET) (specific surface area), and " $\rho$ " is the density of powder particles. By replacing the variables, the average size of each glass ionomer particle was measured to be approximately $3.656 \mu \mathrm{m}$. After relevant calculation, the density of the powder was determined to be $2.2 \mathrm{gr} / \mathrm{cc}\left(\rho=M_{\mathrm{Glass}} / V_{\mathrm{Glass}}=2.2 \mathrm{gr} / \mathrm{cc}\right)$.

\subsection{Scanning Electron Microscope (SEM) and Energy Disper-} sive X-Ray Analysis (EDXA). Figure 2 shows the ceramic part of produced glass ionomer cement. The point noticed by the images is the irregular shape and the size of less than 100 micrometer of the glass particles. The SEM images from the integrated glassy structure of glass ionomers (mixture of glass ionomer powder and polymer liquid (polyacrylic acid)) are shown in Figure 3. The produced ceramic part was properly mixed with the polymer liquid, and subsequently the glass ionomer cement was properly strengthened. The rather homogeneous and flat surface of glass ionomer is clearly observed in the images taken by SEM.

The identified chemical elements in glass cement and their weight percentages that were obtained using energy dispersive X-ray analysis (EDXA) are seen in Table 3. The identified carbon in the cement is related to the existing carbon in carboxylic acid (the polymer part of glass ionomer cement). Other identified elements are related to the ceramic part of cement and are as expected. Strontium is also observed in the results obtained from the chemical compound analysis and is as expected, too, although the weight percentages of the elements obtained by this method are not quite accurate.

3.4. X-Ray Fluorescence Analysis (XRF). Element analysis by $\mathrm{XRF}$ method was performed on glass ionomer powder to confirm the presence of oxides in the compound, according to the considered weight percents. The resulted findings were similar to the calculated composition for the sample (Table 2). This result showed that the chemical compounds of the ceramic part of glass ionomer cement by the melting method were to a great extent similar to the expected weight rates.
TABLE 2: The amount of the existent materials in produced glass ionomer (X-ray fluorescence analysis result).

\begin{tabular}{lcc}
\hline $\mathrm{Wt} \%$ & Chemical composition & Compounds \\
\hline 39 & $\mathrm{SiO}_{2}$ & Quartz \\
25.5 & $\mathrm{Al}_{2} \mathrm{O}_{3}$ & Alumina \\
16.5 & $\mathrm{AlPO}_{4}$ & Aluminum phosphate \\
12 & $\mathrm{CaF}_{2}$ & Fluorite \\
7 & $\mathrm{SrF}$ & Strontium fluoride \\
\hline
\end{tabular}

TABLE 3: The amount of detected elements in produced glass ionomer cement (result of X-ray energy distribution analysis (EDXA)).

\begin{tabular}{lcc}
\hline $\mathrm{Wt} \%$ & Intensity $(\mathrm{c} / \mathrm{s})$ & Element \\
\hline 11.358 & 35.75 & $\mathrm{C}$ \\
32.726 & 381.01 & $\mathrm{O}$ \\
15.656 & 1092.85 & $\mathrm{Al}$ \\
25.883 & 1390.93 & $\mathrm{Si}$ \\
5.941 & 299.49 & $\mathrm{P}$ \\
5.410 & 359.35 & $\mathrm{Ca}$ \\
3.30 & 235.2 & $\mathrm{Sr}$ \\
\hline
\end{tabular}

3.5. Bioactivity Evaluation of Glass Ionomer Cement in the Simulated Body Fluid (SBF). The potential of apatite formation in SBF was considered and analyzed on the surface of glass ionomer cement as one of the signs of bioactive behavior.

3.6. Evaluation of Bioactivity by SEM. The amount of participated apatite on the surface of glass ionomer powder was considered by SEM. It is to note that comparison of SEM images is totally qualitative. The surface of glass ionomer cement before soaking in SBF is shown in Figure 4(a). Figures 4(b) and 4(c) show the surface of the same sample after 28 days of soaking in the fluid. As it can clearly be seen, the rather flat and homogeneous surface of the cement has been transformed to a rather porous and inhomogeneous surface after the soaking. The lighter color dispersed particles are the apatite particles participated on the cement surface from the simulated body fluid. Since glass ionomer cement is not recognized as a bioactive ceramic, the very little formation of apatite compounds on it is quite well justified.

\subsection{Evaluation of Bioactivity Using Fourier Transform Infrared} Spectrometer (FTIR). The results of bioactivity evaluation of glass ionomer powder, carried out by fourier transform infrared spectrometer, are shown in Figure 5. Figure 5(a) shows the glass ionomer cement powder sample before soaking in SBF, and Figure 5(b) is related to the powder sample after soaking in SBF for 28 days at the temperature of $37^{\circ} \mathrm{C}$. As it can be observed in Figure 5(a), there are three peaks related to vibrations $v_{1}, v_{3}$, and $v_{4}$, from phosphate groups clearly identified in the apatite compound. The related peaks to vibrations $v_{1}, v_{3}$, and $v_{4}$ have appeared in wavelength of $465 \mathrm{~cm}^{-1}, 974 \mathrm{~cm}^{-1}$, and $1112 \mathrm{~cm}^{-1}$, respectively. Created peaks at wavelengths $1398 \mathrm{~cm}^{-1}$ and $1625 \mathrm{~cm}^{-1}$ are, respectively, related to symmetric and asymmetric tensile 


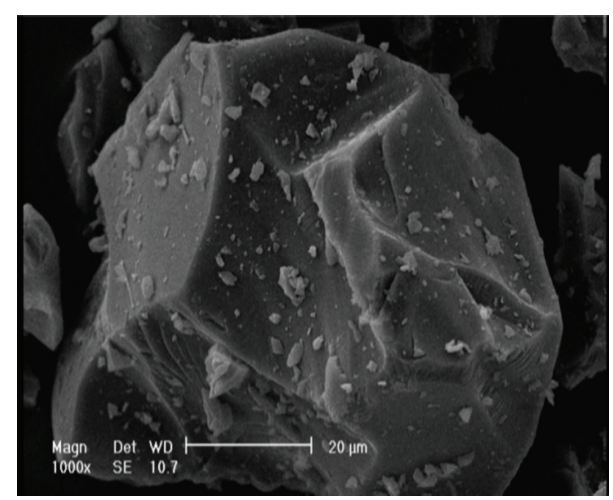

(a)

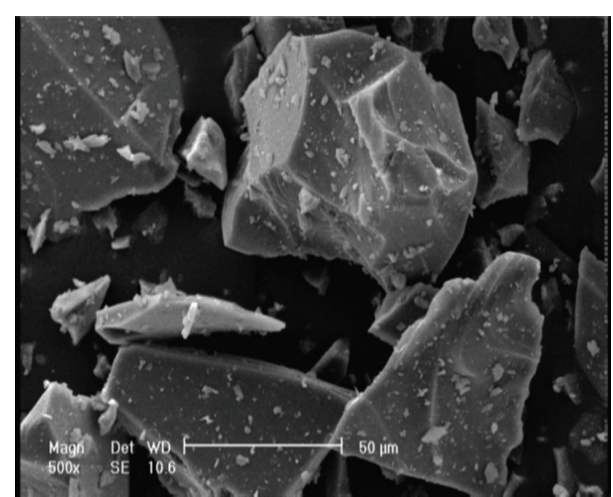

(b)

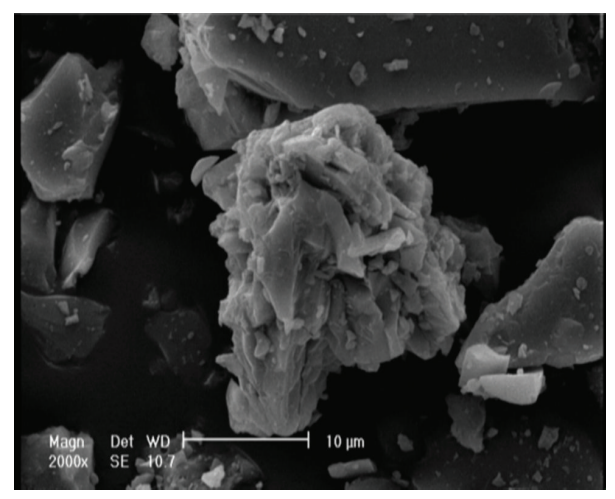

(c)

FIGURE 2: The SEM images of ceramic parts of the glass ionomer cement in different magnifications.

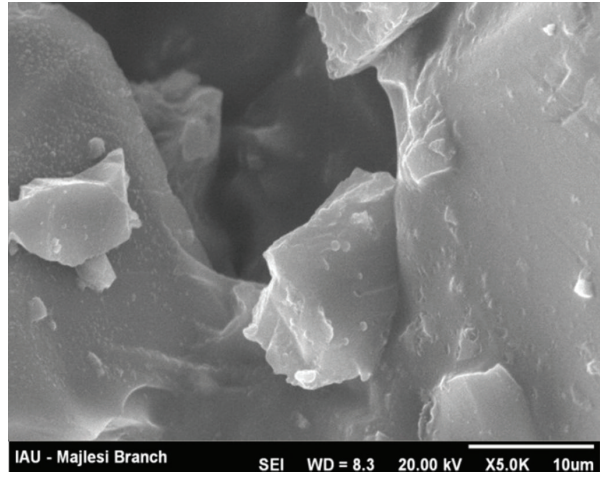

(a)

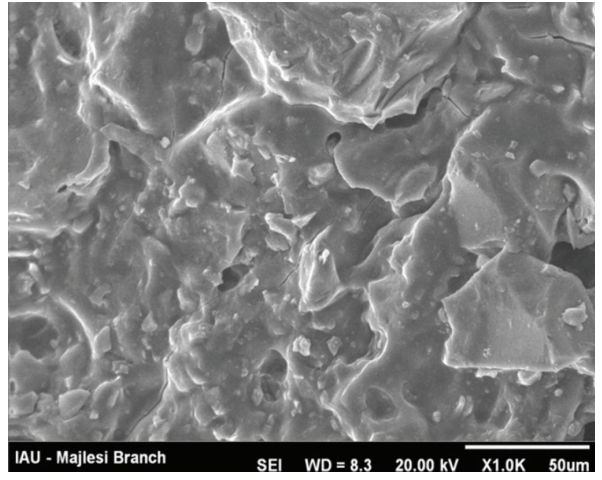

(b)

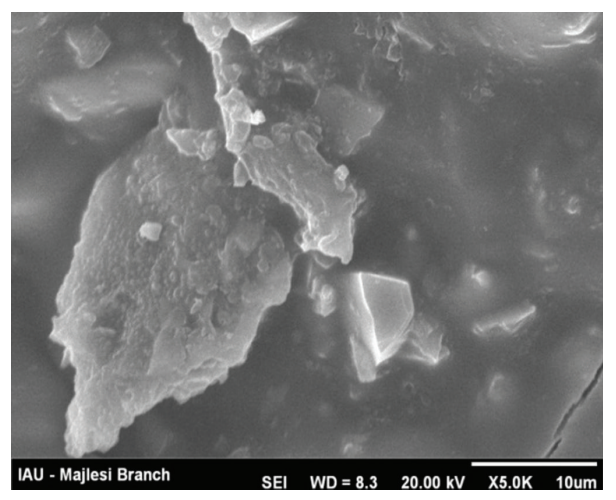

(c)

FIGURE 3: The SEM images of glass ionomer cement (ceramic part mixed with polyacrylic acid liquid) in different magnifications. 


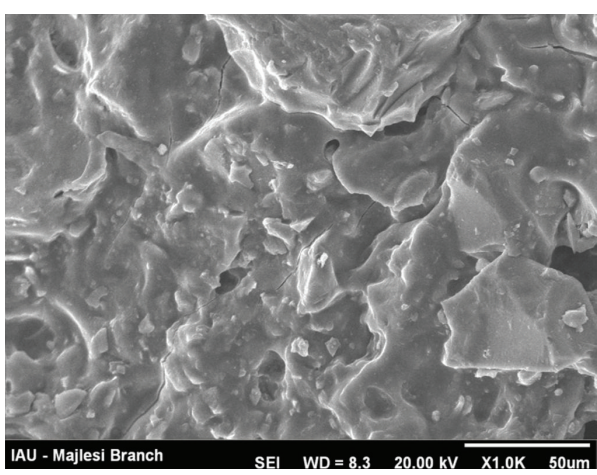

(a)

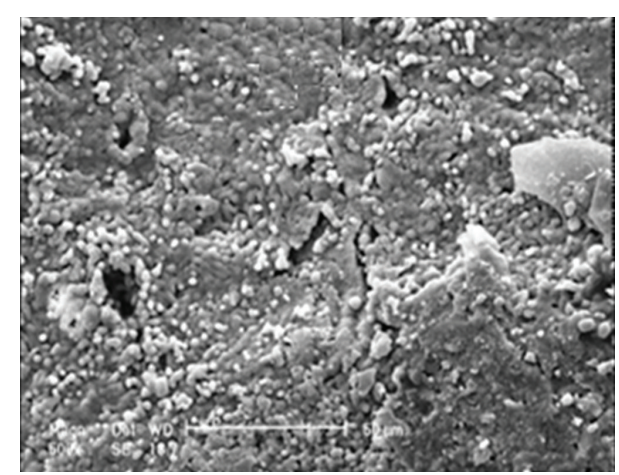

(b)

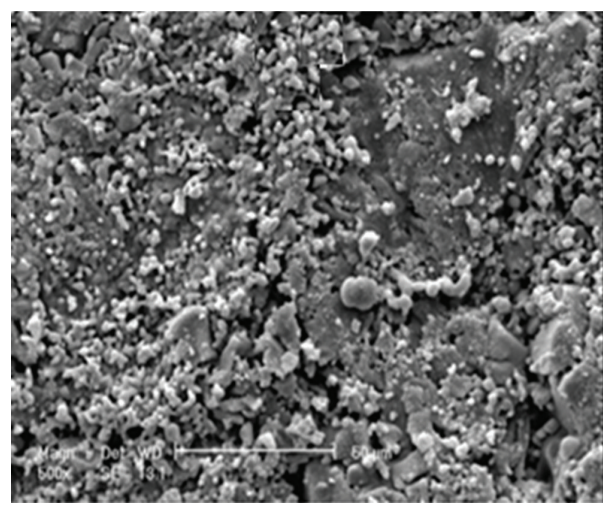

(c)

FIGURE 4: The surface area of the glass ionomer cement sample, before (a) and after (b) (c) soaking in the simulated body fluid.

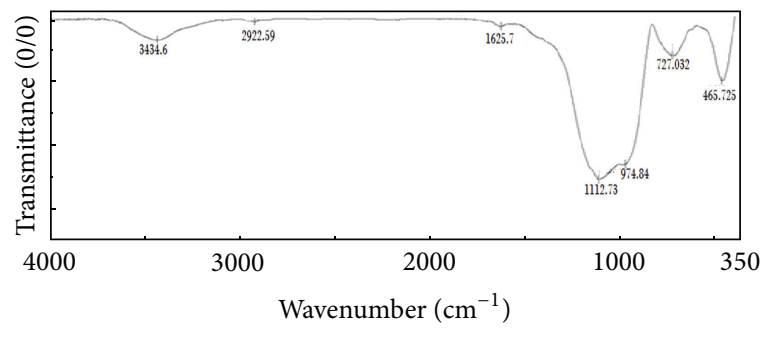

(a)

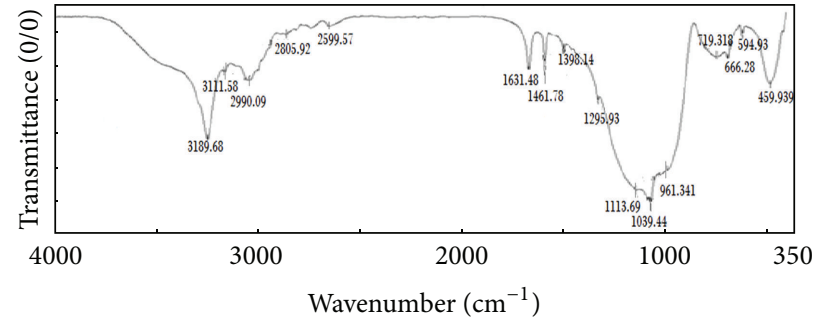

(b)

FIGURE 5: FTIR spectra of the glass ionomer cement: (a) before soaking in SBF, (b) after 28 days of soaking in SBF.

vibrations of $\mathrm{COO}^{-}$(in carboxylic acid salt compounds) in glass ionomer cement powder [13, 14]. Finally, the two observed peaks at wavelengths $666 \mathrm{~cm}^{-1}$ and $3434 \mathrm{~cm}^{-1}$ are related to hydrostructures in the glass ionomer compound.

By increasing the soaking time of glass ionomer powder, it is expected that [13]

(i) the relative intensity of phosphate peaks is to increase;

(ii) $\mathrm{C}-\mathrm{O}$ tension in $\mathrm{CO}_{3}{ }^{-2}$ groups is to be observed within the range of $1413-1453 \mathrm{~cm}^{-1}$;

(iii) a wide peak is to be observed at $1530-1650 \mathrm{~cm}^{-1}$ range.

Phosphate peaks in Figure 5(b) had relative increase in the ranges of $465-594 \mathrm{~cm}^{-1}$ and $960-1200 \mathrm{~cm}^{-1}$. The C-O tensile peak is observed at the wavelength of $1461 \mathrm{~cm}^{-1}$, and the presence of this peak confirms the formation of apatite carbonate layer on the surface of glass ionomer powder [14-16]. Also, the established peaks at $1555 \mathrm{~cm}^{-1}$ and $1631 \mathrm{~cm}^{-1}$ express that some of the carboxylate salt compounds are formed on the soaking powder.

The obtained results from FTIR show that the produced powder has an appropriate bioactive behavior.

\section{Discussion}

The results of X-ray diffraction showed that the produced glass ionomer powder has a completely amorph and glassy structure. The results indicate the formation of a glass structure in glass cement. The obtained results were in 
conformity with the reported results by Hesaraki et al. [7] and Moshaverinia et al. [11]. The obtained sizes of glass particles (less than 100 micrometer) had proper conformity with the commercial example (Fuji, Japan). The irregular shape of the particles is due to milling them after getting the solidified melt. The more the time of milling is, the more the particles sizes will be smaller. The size of less than 100 micrometer for the glass particles produced by the melting method has also been reported by the researchers. The size of glass particles has great role in their performance after being mixed with polymer liquid (polyacrylic acid). The SEM images of the glass cement (mixed powder with the liquid) indicate an integrated glass phase of produced glass ionomer. Integrity and homogeneity of the final phase have great effects on the clinical performance of glass cement.

The result from analyzing the chemical compound of glass cement showed that the chemical compound of the ceramic part of glass ionomer cement produced by the melting method is to a great extent proportional to the expected weight percent of the materials. Existence of strontium in the glass compound will improve the mechanical properties as well as the clinical performance and biological characteristics of the cement. This has also been proved by other researchers [7].

Regarding the history of strontium, this element $(\mathrm{Sr})$ is one of the ions known to reduce bone resorption and accelerate bone healing processes. Consequently, several studies have been also conducted on the use of $\mathrm{Sr}$ ions in the composition of bioceramic-based biomaterials. Landi et al. [17] synthesized Sr-substituted hydroxyapatite and studied its mechanical, physicochemical, and structural properties. There are, however, limited studies on strontium-containing bioactive glass bone substitutes. The role of Sr on the structure and reactivity of dental ionomer glasses has been reported by Boyd et al. [18]. Abou Neel et al. [19] reported some structural and physical characteristics of melt-derived phosphate glasses based on $\mathrm{Na}_{2} \mathrm{O}-\mathrm{CaO}-\mathrm{SrO}-\mathrm{P}_{2} \mathrm{O}_{5}$ system. Both in vitro reativity and in vivo reactivity of a melt-derived bioglass system based on $\mathrm{SrO}-\mathrm{CaO}-\mathrm{ZnO}-\mathrm{SiO}_{2}$ were also evaluated by Towler et al. [20], and it was found from their results that the glass is incapable of forming an apatite layer in simulated body fluid (SBF). Against this result, Hesaraki et al. showed that adding Sr to calcium silicophosphate glasses will improve the apatite layer formation in simulated body fluid (SBF) [7].

As stated before, the obtained results from SEM and FTIR showed that the chemical reaction of glass ionomer powder with regard to the simulated body fluid (SBF) leads to participation of apatite layer on the powder surface. Formation of apatite layer after soaking in SBF indicates that the glass ionomer cement is bioactive [11]. Hence, the produced glass ionomer powder in this research could be used in dentistry and even orthopedic cases as a bioactive material.

\section{Conclusions}

The results from this study demonstrate that the strontiumcontaining glass ionomer cement can be produced using melting method. The characterization tests confirmed the glassy structure of the produced ionomer cements. The result of XRF confirmed the presence of $\mathrm{Sr}$ in the chemical composition. FTIR and SEM confirmed the formation of apatite layer on the surface of material. Therefore, the produced glass ionomer powder in this research is a bioactive material. Also, existence of strontium in the glass compound will improve the bioactivity of GIC in simulated body fluid. The final result of this research was producing glass ionomer cement containing Sr with improved in vitro bioactivity.

\section{References}

[1] G. Mount and W. Hume, Preservation and Restoration of Tooth Structure, Mosby, 1998.

[2] R. R. Mccaghren, D. H. Retief, E. L. Bradley, and F. R. Denys, "Shear bond strength of light-cured glass ionomer to enamel and dentin," Journal of Dental Research, vol. 69, no. 1, pp. 4045, 1990.

[3] P. Samimi and K. Fatehpour, Viscosity in Dentistry, Manny Press, Collaboration of University of Isfahan Medical Science, 2002.

[4] R. Philips and W. Alph, "The glass ionomer cements," Journal of the American Dental Association, vol. 120, pp. 19-20, 1990.

[5] J. Swift and A. U. Dogan, "Analysis of glass ionomer cement with use of scanning electron microscopy," The Journal of Prosthetic Dentistry, vol. 64, no. 2, pp. 165-174, 1990.

[6] J. Bagheri, Glass Ionomer Cements, Imam Reza University, Mashhad, Iran, 2004.

[7] S. Hesaraki, M. Alizadeh, H. Nazarian, and D. Sharifi, "Physico-chemical and in vitro biological evaluation of strontium/calcium silicophosphate glass," Journal of Materials Science, vol. 21, no. 2, pp. 695-705, 2010.

[8] Dousti, Fundamental of Clinical Uses of Glass Ionomer, Payam Hojat Press, Quom, Iran, 2007.

[9] Arastoporak, Knowledge and Art in Strontium Dentistry, Shyan Nemoudar, 2002.

[10] A. Todo, M. Hirasawa, and S. H. Kato, "Glass powder for dental glassionomer cement," United states patent Number: 6, 136, 737.

[11] A. Moshaverinia, S. Ansari, M. Moshaverinia, N. Roohpour, J. A. Darr, and I. Rehman, "Effects of incorporation of hydroxyapatite and fluoroapatite nanobioceramics into conventional glass ionomer cements," Acta Biomaterialia, vol. 4, no. 2, pp. 432-440, 2008.

[12] A. Doostmohammadi, A. Monshi, R. Salehi et al., "Preparation, chemistry and physical properties of bone-derived hydroxyapatite particles having a negative zeta potential," Materials Chemistry and Physics, vol. 132, no. 2-3, pp. 446-452, 2012.

[13] J. Nourmohammadi, S. K. Sadrnezhaad, and A. Behnamghader, "In vitro bioactivity of novel cured ionomer cement based on iron oxide," Ceramics International, vol. 36, no. 5, pp. 1645-1651, 2010.

[14] G. Xu, I. A. Aksay, and J. T. Groves, "Continuous crystalline carbonate apatite thin films, a biomimetic approach," Journal of the American Chemical Society, vol. 123, no. 10, pp. 2196-2203, 2001.

[15] Y. Li, T. Wiliana, and K. C. Tam, "Synthesis of amorphous calcium phosphate using various types of cyclodextrins," Materials Research Bulletin, vol. 42, no. 5, pp. 820-827, 2007.

[16] G. Socrates, Infrared and Raman Characteristic Group Frequencies, Tables and Charts, John Wiley \& Sons, Chichester, UK, 2006. 
[17] E. Landi, A. Tampieri, G. Celotti, S. Sprio, M. Sandri, and G. Logroscino, "Sr-substituted hydroxyapatites for osteoporotic bone replacement," Acta Biomaterialia, vol. 3, no. 6, pp. 961-969, 2007.

[18] D. Boyd, M. R. Towler, S. Watts, R. G. Hill, A. W. Wren, and O. M. Clarkin, "The role of $\mathrm{Sr}^{2+}$ on the structure and reactivity of SrO-CaO-ZnO-SiO ${ }_{2}$ ionomer glasses," Journal of Materials Science, vol. 19, no. 2, pp. 953-957, 2008.

[19] E. A. Abou Neel, W. Chrzanowski, D. M. Pickup et al., "Structure and properties of strontium-doped phosphate-based glasses," Journal of the Royal Society Interface, vol. 6, no. 34, pp. 435-446, 2009.

[20] M. Towler, D. Boyd, C. Freeman, I. M. Brook, and P. Farthing, "Comparison of in vitro and in vivo bioactivity of SrO-CaO$\mathrm{ZnO}-\mathrm{SiO}_{2}$ glass grafts," Journal of Biomaterials Applications, vol. 23, no. 6, pp. 561-572, 2009. 

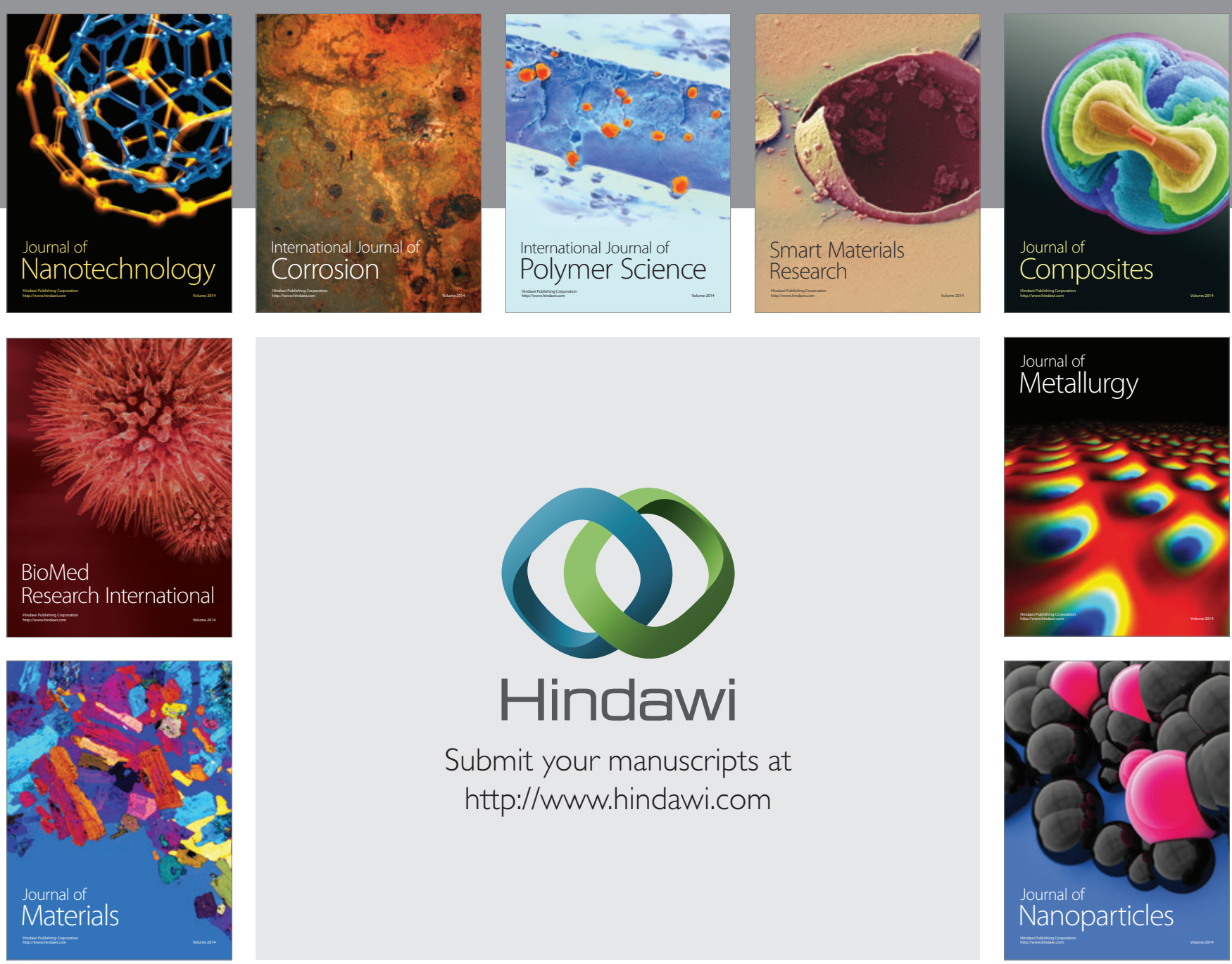

Submit your manuscripts at http://www.hindawi.com
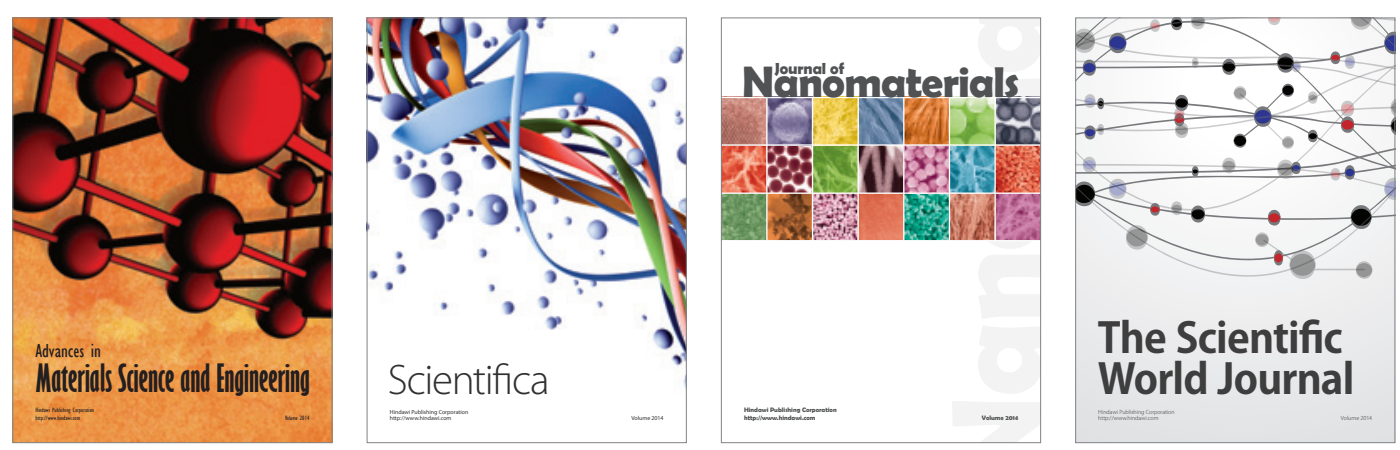

\section{The Scientific World Journal}
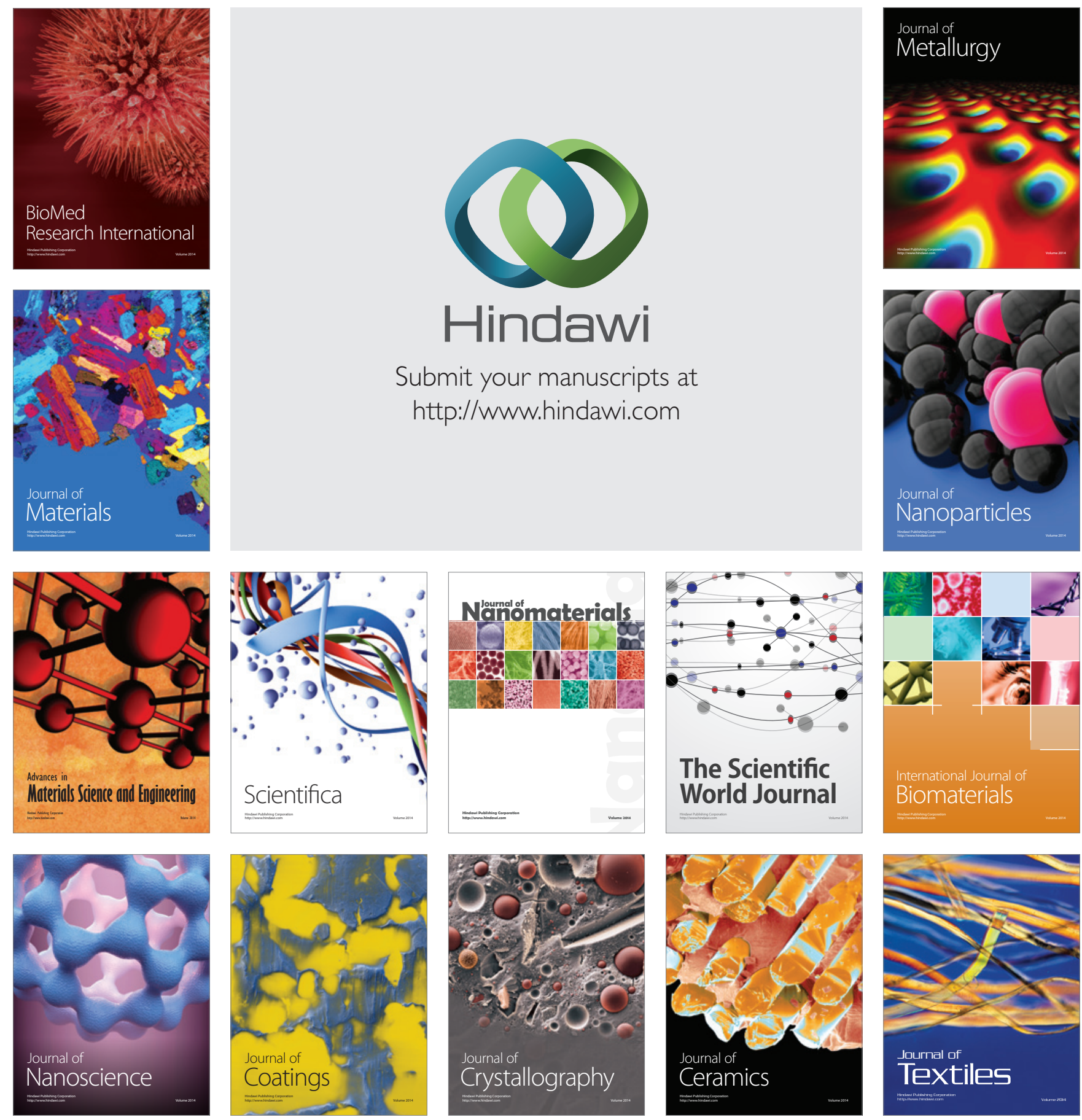